\title{
Rede quilombola de Sergipe e organização política da CEMQS
}

\section{Ruth Paes Ribeiro \\ Universidade Federal de Sergipe}

Resumo: Este artigo descreve parte das (medi) ações mobilizatórias de um grupo de lideranças quilombolas do Estado de Sergipe. Através de inserções etnográficas nos eventos públicos, bem como nos espaços de reuniões mensais (RMs) para a organização da "Coordenação Estadual do Movimento Quilombola de Sergipe" (CEMQS), observou-se a (pré) existência e (re) formação de uma rede de atores, agências e coisas em torno da política pública voltada para os chamados quilombolas do Estado.

Palavras-chave: rede quilombola; mediação; direitos sociais; voz pública; movimentos sociais. 


\title{
Sergipe quilombola network and political organization of CEMQS
}

\begin{abstract}
This paper describes the actions of a group of quilombola leaders in the state of Sergipe, in brazilian northeast. Through ethnographic inserts in the public events, as well as in the spaces of monthly meetings to organize the "State Coordination of Quilombola Movement" is observed to (pre)existence and (re)formation of a network of actors, agencies and "things" around the public policy toward the called quilombolas in the state.
\end{abstract} Sergipe.

Keywords: quilombola network; mediation; public voice; social rights;

\section{Red quilombola de Sergipe y la organización política de la CEMQS}

Resumen: En este artículo se describe parte de la acciones mobilizatórias de un grupo de líderes quilombolas de Sergipe. A través de inserciones etnográficas en eventos públicos, así como en los espacios de reuniones mensuales para la organización de "Coordinación Estatal del Movimiento Quilombola de Sergipe" (CEMQS), se observó a la existencia y (re) formación de una red de actores, agencias y cosas alrededor de la política pública centrada en los llamados cimarrones.

Palabras clave: Red quilombola, mediación; derechos sociales; voz pública; movimientos sociales; Sergipe. 


\title{
"Ói! Quilombola tem que ter uma fala só”1
}

\begin{abstract}
E quantos movimentos existiam (...)? Não! Porque daqui a pouco, tem uma quebra de braço, porque tem gente ligada à Caritas, tem gente ligada ao MST. Eu disse: "Ói! Quilombola tem que ter uma fala só!” (...) quando nós falamos de comunidade quilombola, é comunidade quilombola! Não é movimento dos sem-terra, não é movimento de Igreja, ou outro movimento, etc., é movimento quilombola! Então, é isso que eu defendo, eu sempre defendi, minha tese é essa2.
\end{abstract}

Como se processa o surgimento de um movimento que emerge "às avessas"? Dizemos: onde primeiramente os direitos são (aparentemente) dados, sistematizados ou conhecidos, para depois serem (auto) reivindicados? Referimo-nos a um movimento que surge através de um trabalho repartido entre diferentes instâncias (mediadoras) e que, agora, reivindica uma "fala"3 dita "por eles mesmos". O pano de fundo do texto indaga a seguinte questão: até que ponto a existência de um cenário onde diferentes agências que atuam, de algum modo, em defesa dos direitos concernentes às Comunidades Quilombolas no estado de Sergipe, relaciona-se com a maneira pela qual a CEMQS irá organizar-se? Como ceder espaço a atuação de um movimento constituído "apenas de quilombolas" - sujeitos estes mais fixados em âmbitos "locais" (ANJOS E SILVA, 2008, p.160) - quando outros atores sociais com elevados potenciais de mobilidade no interior das redes4 de mediação disputam - direta ou indiretamente - tal representação?

Lançado em 2004, o Programa "Brasil Quilombola" busca empreender um conjunto de ações com o intuito de amenizar os contrastes socioeconômicos e políticos vividos na sociedade brasileira, por meio de uma política redistributiva, tendo como público alvo, sobretudo, as populações negras rurais do Brasil. Neves (2005) afirma que "esse é um fato raro no país, onde a revalorização da identidade é acompanhada de uma perspectiva redistributiva visível, o que talvez explique a participação ativa da população negra não militante em uma ação política de cunho racial” (NEVES, 2005; p. 88; grifos nossos).

${ }^{1}$ Expressão usada por Robério, coordenador da CEMQS, em Evento VI (Primeiro Encontro Nacional de Fortalecimento da Cadeia Produtiva das Comunidades Quilombolas do Estado de Sergipe. Primeiro encontro realizado pela CEMQS junto à CONAQ, PNUD e CONSEAN. Hotel Hiverside. Aracaju. Maio de 2014). Todos os atores citados neste trabalho são coordenadores da CEMQS; os que não forem serão devidamente discriminados.

2Idem.

3 "Fala" - acepção nativa - será entendida aqui, de um modo geral, como sinônimo de autorrepresentação dos quilombolas em espaços públicos voltados ou relacionados à Política Pública para quilombos no Estado. "Ter fala" é, especificamente, poder usar da voz, perante autoridades e/ou demais lideranças quilombolas (quando se trata da organização "interna") para dizer sobre direitos sociais e "problemas" vividos nos quilombos de Sergipe.

4 Nesta "rede quilombola", encontram-se atores oriundos do meio rural interagindo com outros advindos do meio urbano, ambos, ligados agora, por uma Política Pública nacional: o Programa Brasil Quilombola. A rede que trataremos aqui é, em grande medida, o que Anjos e Silva definiram como "rede ampla, de elaboração e aplicação de políticas públicas [voltada para os quilombolas]" (2008, p. 157), na qual introduzem-se sujeitos diversos, com interesses também variados, vivenciando um "mundo comum", ou o que Thévenot e Boltanski chamaram de "cidade" (DODIER, 1993, p. 80). Mais precisamente, em três tipos de cidades ou "lógicas de justificação" inscritas, de acordo com Boltanski e Chiapello (2009), numa sociedade cada vez mais conectada por redes, ou seja, a cidade por projetos, onde as "políticas de luta contra a miséria" enquadram-se como um de seus dispositivos, sobretudo, por pretenderem, ao frear a exclusão, reintegrar pessoas (BOLTANSKI; CHIAPELLO, 2009, p. 406); há ainda as "cidades domésticas", onde a grandeza das pessoas depende de sua posição hierárquica numa cadeia de dependências pessoais; e "cívica", onde o "grande" é o representante de um coletivo cuja vontade geral ele exprime (id., ibid., p. 57). A rede em torno da política pública para quilombos no Estado de Sergipe trata-se, também, daquilo que Barnes (2010) mencionou como rede "idiossincrática" ou constituída de relações "que são pessoais, ou seja, que derivam do status de uma pessoa como amiga, patrono ou algo semelhante" (BARNES, 2010, p. 202). É, também, uma rede sociotécnica (LATOUR, 1994), permeada por um coletivo ou agregado (LATOUR, 2012), composta por conexões entre humanos e não humanos (agente do governo, partidos, técnicos de ONGs, artefatos técnicos, sala de reuniões, etc.). 
Todavia, Santos (2014) afirma que mesmo com o "aprimoramento dos dispositivos legais, que garantam às comunidades negras rurais e urbanas o direito à terra e território, percebe-se certa lentidão do Estado Brasileiro em, de fato, garantir este direito" (SANTOS, 2014; p. 80). O mesmo autor diz, ainda, que "se tal letargia continuar, além de estimular novos conflitos as comunidades negras rurais (...) terão seus processos fundiários conclusos de fato em 2.188" (p.80) - das 29 comunidades quilombolas certificadas em Sergipe, por exemplo, apenas quatro possuem títulos que são parciais5, o que representa, apenas, $14 \%$.

Segundo Gohn (2011), os movimentos podem surgir e desenvolver-se, também, a partir de uma reflexão sobre sua própria experiência (id., ibid., p. 336). A CEMQS vai surgindo a partir do contato de várias lideranças6 com este novo universo da participação em eventos após o PBQ7: seminários, reuniões, congressos, etc., bem como através da relação com o Comitê Gestor, um dos nomes representativos de quilombos no Estado. Além disso, as lideranças quilombolas possuem experiências variadas com estas mesmas agências que atuam direta ou indiretamente em políticas públicas para quilombos em Sergipe, dentre as principais: o INCRA, a Cáritas Diocesana de Propriá8, o MST9, o Movimento Negro, através da SEDHUC10 - que possui (até 2014) atores ligados a um histórico de engajamento na causa racial no Estado -, o MNU, o Instituto Braços (IB)11, o quilombo urbano da Maloca, por exemplo. Muitas destas organizações são constitutivas da "gênese" de mobilização política de algumas comunidades quilombolas no Estado, no que tange à solicitação do autorreconhecimento da Fundação Cultural Palmares12.

A CEMQS, a “coordenação estadual” ou, simplesmente, a "coordenação”, como eles se autorreferenciam, são nomes ou diferenciações que expressam a criatividade de alguns atores em controlar uma "riqueza" bastante disputada na rede quilombola do Estado: a fala, ou o ato de autorrepresentar-se. A CEMQS é uma "objetificação do controle" (WAGNER, 2010b, p. 90), podemos dizer, assim como Wagner (2010a) - ao criticar o uso de conceitos ditos "antecipadamente" -, que os nomes em grande medida "delineiam um modo de criatividade cujo aspecto mais sério, ao menos em termos nativos, é o da troca de riquezas. Essa troca, por sua vez, deriva de outro uso do contraste e da distinção para eliciar relações sociais" (p. 247).

A fim de controlar o acesso aos espaços de representação política das Comunidades Quilombolas no Estado, bem como o acesso a direitos sociais, o "nome", estabelece fronteiras entre os quilombolas e os não-quilombolas da rede. Os contrastes que aqui pudemos notar foram com relação ao "Governo", representado nas situações, pelo INCRA, pela SEDHUC e pelo Comitê Gestor, bem como com relação a outros atores de atuação no meio rural como o MST, à Cáritas Diocesana de Propriá - uma das peças que compõe o "movimento do

\footnotetext{
5 Pirangy, Mocambo (Porto da Folha), Lagoa dos Campinhos e Serra da Guia (BRASIL, 2015).

6 Tomaremos aqui a acepção "nativa" "lideranças quilombolas" para nos referirmos aos membros das diretorias das Associações Quilombolas, os quais participam de atos de mobilização e articulação para uma organização coletiva das demandas dos quilombolas no estado de Sergipe. Sendo assim, embora seja possível encontrar alguns casos, tornar-se presidente de uma associação quilombola não significa, necessariamente, ser uma "liderança quilombola" reconhecida "internamente", como bem frisou Anjos e Silva (2008).

7 Programa Brasil Quilombola.

8 ONG ligada à Igreja Católica. Propriá é uma cidade localizada no leste sergipano.

9 Movimento dos Trabalhadores Sem-Terra.

10 Secretaria Estadual de Direitos Humanos e Cidadania. A partir de 2015, perdeu status de secretaria e tornou-se uma coordenadoria.

11 Organização não governamental.

${ }_{12}$ Dentre as agências que pudemos verificar como mediadoras dos processos de constituição de algumas Comunidades Quilombolas no estado, podemos citar: a Cáritas Diocesana de Propriá, o MST, o INCRA, o Instituto Braços, Secretarias municipais de assistência social, etc.
} 
Padre"13 -, além de uma diferenciação entre "eles mesmos" ou entre os "coordenadores" e o Comitê Gestor, representado por liderança do quilombo urbano da Maloca.

A coleta de dados - e fatos - se deu em sua maior parte in vivo ou "na constituição de relações de familiaridade e confiança com os interlocutores [...]" (CEFAI et al., 2011, p. 11), ou derivada da minha co-participação em eventos. O tempo para apreensão destes dados foi de dois anos - de junho de 2013 a junho de 2015 - e dividiu-se em 6 procedimentos correlacionados: 1) Observação e participação em eventos públicos; 2) Observação e participação em reuniões mais "privadas" da CEMQS - as "RMs14" -, totalizando vinte e quatro eventos15, onde estiveram lideranças quilombolas; 3) Busca de informações em sites governamentais e de notícias, além de pesquisa de informações veiculadas às redes sociais virtuais, como Facebook; 4) acesso à documentação pública (física) do INCRA e MPF; 5) aplicação de um questionário supervisionado e, por último, 6) a realização de três entrevistas.

Por fim, a CEMQS não "é" sem aqueles "outros" aos quais ela se opõe e que a ela se complementam. Gostaríamos, assim, de fazer uma breve demonstração de parte da rede quilombola, ou, mais precisamente, dos principais atores - e dilemas - quilombolas e não-quilombolas que, de algum modo, influenciaram sua formatação, os quais relacionam-se, direta e constantemente com o grupo.

\section{O "movimento do padre"}

A justificativa de que o Comitê Gestor16 era "governo" a fim de legitimar a criação de mais um formato de organização, não era a única que contribuía para legitimar a necessidade de distinção ou diferenciação "entre eles" e os "outros". Outras "censuras" eram empreendidas com a finalidade de restringir ou garantir um espaço da atuação e fala dos quilombolas sobre as políticas públicas voltadas para quilombos nos Estado de Sergipe. Uma das censuras era em relação ao envolvimento de algumas comunidades quilombolas com a Cáritas Diocesana de Propriá ou com o Padre, além do Instituto Braços junto ao Movimento Nacional de Direitos Humanos. Este arranjo tratava-se de uma "rede parcial" (MAYER, 2010) em torno das ações que envolviam quilombos no Estado - ou circunscritas em uma rede total, que não descreverei aqui -, o que parecia "um movimento próprio" - ou o "movimento do Padre" - na medida em que, por vezes, era visto, por algumas lideranças, como concorrente das ações de um movimento que tivesse "uma fala só” - ou só dos quilombolas.

\footnotetext{
${ }^{13}$ Expressão utilizada por uma liderança ao se referir ao que chamamos de "rede parcial de apoiadores" (MAYER, 2010). Conversa informal. Aracaju, INCRA, março de 2013.

14 Reuniões mensais.

${ }^{15}$ Neste artigo, os vinte e quatro eventos aparecerão numerados.

${ }^{16}$ Falaremos sobre o Comitê Gestor no tópico seguinte.
} 


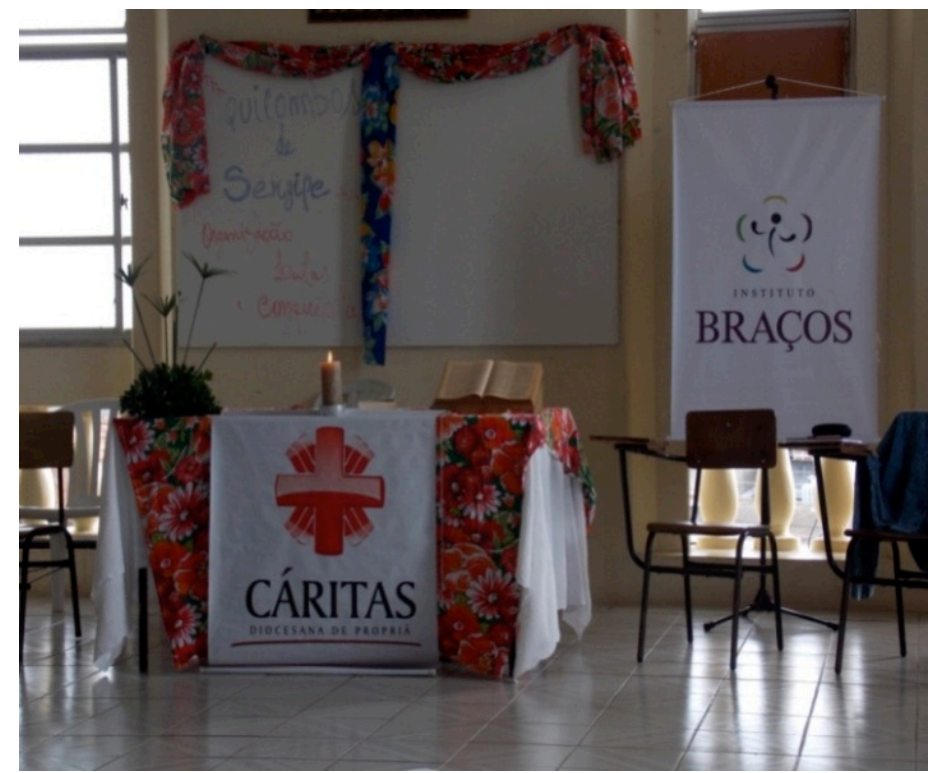

Figura $\mathrm{I}^{17}$

Brejão dos Negros e Caraíbas eram duas das comunidades quilombolas que tinham relações diretas com esta rede parcial de apoiadores. A atuação da Cáritas Diocesana de Propriá nas duas comunidades, de modos diferentes, acabou (de certo modo) por torná-las mais visíveis no cenário das aparições públicas em Sergipe. Em Brejão dos Negros, o padre foi o agente que despertou o interesse da comunidade em requerer a certidão pela $\mathrm{FCP} 18$, realizando um trabalho de conscientização através da Igreja:

Mas a gente só foi despertando com a presença do Padre. Por que a gente não enxergava, não enxergava isso. A gente era cego mesmo, a gente estava ali sendo escravo e não sabia e ainda achava que estava bom (...)19.

Em Caraíbas, os próprios técnicos da Cáritas Diocesana de Propriá quando estes prestavam assessoria em um assentamento vizinho à CQ20 foram acionados por moradores da comunidade, os quais, na época, interessavam-se em ser "assentados da reforma agrária":

Rose [ex-técnica da Cáritas] foi quem foi vendo que a gente tinha características diferentes. Ela que reparou que a gente tinha uma ancestralidade negra e a partir daí começamos a entender o que era a política quilombola. 21

A forte atuação do pároco em defesa da comunidade de Brejão dos Negros, bem como de deputada estadual vinculada ao PT, uma das principais parlamentares de atuação em defesa dos quilombolas no Estado, junto, por outro lado, à confluência de interesses e disputas na região, através da atuação contrária de um deputado estadual ligado ao partido DEM, de uma juíza detentora de propriedade no lugar onde estava o território da CQ, e, ainda, pelo potencial turístico do território, atraindo, inclusive, o interesse de pretensos investidores estrangeiros, tudo isto, de certo modo, darão grande visibilidade à comunidade: "ao contrário de outras"22.

17 Evento I: "Encontro de Propriá", intitulado: "Quilombos de Sergipe. Organização, lutas e Conquistas". Organizado pela Cáritas e pelo Instituto Braços, junto à Associação Quilombola Santa Cruz de Brejão dos Negros. Junho/2013. Foto da autora.

${ }^{18}$ Fundação Cultural Palmares.

19 Entrevista com Isaltina. Evento I.

${ }^{20}$ Comunidade Quilombola.

${ }^{21}$ Conversa informal com Xifroneze. Aracaju. Abril de 2015

${ }^{22}$ Muitas lideranças quilombolas criticavam a atenção que estas duas CQs (Brejão dos Negros e Caraíbas) recebiam. 
Decerto, a CQ de Brejão dos Negros acaba por destacar-se mais - p. ex., o número de matérias que circulam na internet, tanto no site da Assembleia Legislativa, quanto em outros. Há recorrentes falas e eventos onde aquela deputada aparece junto a comunitários do quilombo e ao pároco, defendendo Brejão dos Negros. Houve o curso da "Escola de Fé e Política" dado à comunidade por este mesmo padre, junto à Cáritas Diocesana de Propriá, no início de 2012. Houve a efetivação de parceria entre INCRA e SEIDES23 - na época em que a deputada estadual era secretária de Estado - a fim de operacionalizar projeto de "resgate cultural" na CQ em 2011 -, com a produção de um vídeo e uma cartilha que circulam pelo Estado. O prêmio concedido ao Padre, em 2013, no Seminário Nacional de Direitos Humanos e Juventude com a presença da deputada e de algumas LQs24 de Brejão dos Negros. A inauguração de uma "casa de farinha" em janeiro de 2014 na CQ de Brejão dos Negros, "dada" pela deputada, etc. Além de uma "ocupação" realizada no INCRA, no início de 2014 - quando a CEMQS já havia sido criada -, com a presença do Padre, do MNDH e do IB, sem o apoio das demais comunidades quilombolas, além de Brejão dos Negros. De modo geral, tudo isto denota um trabalho realizado na e para a CQ de Brejão dos Negros.

Nesta conjuntura de apoiadores, o Instituto Braços (IB), ONG referenciada como "Centro de Defesa dos Direitos Humanos de Sergipe"25, trabalhou dando suporte estrutural às ações do $\mathrm{MNDH}$, através, também, do apoio da mesma deputada ligada ao PT. No tocante ao trabalho com Comunidades Quilombolas, a ONG executa projetos de assessoria técnica e jurídica tanto a Brejão dos Negros, quanto a CQ de Caraíbas, através de projetos financiados pelo Governo Federal. Na ONG, havia, também, alguns integrantes que possuíam trajetória de atuação no movimento negro e alguns deles já haviam atuado, inclusive, em processos de organização política de algumas comunidades quilombolas, a fim de requerer da FCP certificação: "a relação dos membros do Instituto Braços com as comunidades quilombolas de Sergipe se deu desde a luta pela organização e reconhecimento da primeira comunidade remanescente de quilombo, no início dos anos de 1990, a comunidade quilombola de Mocambo"26:

Robson [na época, coordenador geral do IB] procurou a gente pra saber se queríamos que eles desenvolvessem projeto nas nossas CQs. Do mesmo jeito que me procurou, procurou outras. Algumas não aceitaram, como Patioba e Maloca. Nós aceitamos e hoje ele tá lá fazendo trabalho27. (2008):

Estes técnicos da ONG são como aqueles mediadores descritos por Neves

(...) em grande parte militantes políticos fundamentais no exercício e constituição, de consagração e de divulgação de novos ideais, metas e modos de organização, em geral agregados em torno de alianças estabelecidas por redes de instituições ou movimentos associativos (p. 10).

A maioria de seus membros possui trajetória ligada aos movimentos sociais, em específico, ao Movimento Negro. Contudo, o relacionamento de tais entidades com as lideranças quilombolas nem sempre era visto com "bons olhos". Tal censura, muitas vezes, contribuía para o afastamento de lideranças

\footnotetext{
${ }^{23}$ Secretaria Estadual de Inclusão e Desenvolvimento Social.

${ }^{24}$ Lideranças quilombolas.

25 Informações encontradas no site do IB. http://www.institutobracos.org.br/. Acessado em: 15 de janeiro de 2015, às 10:15.

${ }^{26}$ Disponível no site da ONG.

${ }_{27}$ Xifroneze. Entrevista, abril de 2015.
} 
ou comunidades que porventura possuíssem algum vínculo com estas entidades constituídas de não-quilombolas, como pudemos observar na fala de Isaltina, na ocasião da reunião ocorrida em 21/12/13, evento III28, na Maloca:

\section{(...) outra coisa! É que quem tá lá na comunidade ajudando a gente porque a Cáritas é o nossos pés e nossas mãos. Tudo que a gente precisa lá, se disser: vamos no MPF, a Cáritas tá lá com a gente, desde o início, quem abriu os olhos da gente, quem mostrou todos os caminhos pra a gente foi a Cáritas, gente! Se aqui dissessem hoje, ah! Você tem que decidir, ou você fica com o "movimento" ou vocês ficam com a Cáritas, eu ficaria com a Cáritas.}

Imputar a obrigação de separar as CQs das demais agências constituídas em sua base de não-quilombolas, era, em paradoxo, conviver com o risco de levar as lideranças a se movimentarem "isoladamente", ou através, apenas, de uma mediação constituída de não-quilombolas e/ou, também, através do acesso direto dos representantes das próprias comunidades quilombolas às instâncias públicas que tratavam da política quilombola no Estado. Nesse caso, o INCRA e outras instâncias com mais poder na rede quilombola acabavam por ter a sua capacidade de mediar, ampliada. Portanto, havendo o interesse em construir uma organização - um movimento - capaz de mediar as relações de todas as comunidades com os outros atores envolvidos na política pública para quilombos no Estado era preciso, em muito, encarar as relações das demais lideranças quilombolas com os diversos agentes "exógenos", muitas das vezes, mediadores importantes nos processos de organização política das respectivas comunidades enquanto "quilombolas".

\section{O Quilombo Urbano Maloca e o Comitê Gestor (somente) “das" Comunidades Quilombolas de Sergipe?}

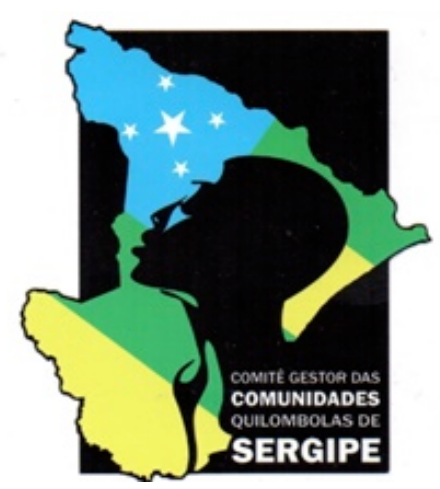

Figura $1^{29}$

O Comitê Gestor da Agenda Social Quilombola, trata-se de uma organização criada pelo Estado Brasileiro. A legislação que institui e regulamenta a existência do Comitê Gestor em nível Federal se dá por publicação em decreto $\mathrm{N}^{0}$ 6.261, de 20 de novembro de 2007 com finalidade descrita no artigo $5^{\mathrm{o}}$ : "propor e articular ações intersetoriais para $\mathrm{o}$ desenvolvimento integrado das ações que constituem a Agenda Social Quilombola”. A criação dos Comitês Gestores estaduais, por outro lado, ocorre

${ }_{28}^{28}$ Reunião no quilombo urbano da Maloca. Marco histórico de formação da CEMQS. Aracaju, 21/12/13.

${ }_{29}$ Símbolo do Comitê Gestor das Comunidades Quilombolas de Sergipe, feito por membros da CRILIBER - abreviação de: "Criança e Liberdade" - ONG localizada no quilombo urbano "Maloca". 
através de "incentivo" da SEPPIR30. Dos Comitês Gestores Quilombolas estaduais no Brasil são poucos os que foram formalizados por decreto. De acordo com dados da SEPPIR, cinco estados, até o ano de 2012, constituíram Comitês, são eles: Alagoas, Amapá, Goiás, Paraíba e Paraná (BRASIL, 2012, p.6).

Até 2014, as comunidades quilombolas de Sergipe utilizavam este "nome" como uma das principais formas de representarem suas ações políticas em Aracaju. Todavia, embora em Sergipe existisse ata que comprovasse o evento "criador" da entidade, e, além disso, a informação de que o ex-governador Marcelo Déda, do PT, tenha assinado um decreto31 para a criação do Comitê Gestor da Agenda Quilombola - em 2008 -, nos registros documentais do governo não foi possível verificar tal existência formal ou regulamentação32. A entidade havia se tornado "algo próprio" das lideranças quilombolas, na medida em que, mesmo diante do fato de as reuniões de "criação" e "eleição" não terem sido seguidas de regulamentação por parte do Governo Estadual, ainda assim, as lideranças significavam - na prática - o termo (Comitê Gestor) como principal símbolo e referência para sua organização.

Certa crença no seu valor "perante o Estado" fazia com que continuassem a se organizar em torno do "nome", independentemente de um entendimento "mais preciso" sobre este instrumento e de sua relevância prática. Em paradoxo, no dia 21 de dezembro de 2013, na Maloca (evento III), a aproximação com este mesmo "governo" ou "Estado", vista na configuração do Comitê Gestor, era acionada pelas lideranças como justificativa principal para criarem uma nova organização. O que isto queria dizer?

De 2008 a 2015, já haviam estado à "frente" do "Comitê Gestor" em Sergipe três lideranças quilombolas. A primeira delas pertencia ao quilombo de Brejão dos Negros33; a segunda, à Comunidade Quilombola de Caraíbas34 e a terceira, e última, ao quilombo urbano da Maloca35. As duas primeiras tiveram a assessoria da Cáritas Diocesana de Propriá que, desde o início - e ainda hoje , estiveram presentes nos processos de organização para o requerimento da certificação enquanto "comunidades quilombolas" à Fundação Cultural Palmares.

Ao contrário das outras duas, o quilombo urbano da Maloca organiza o seu processo de reconhecimento através de uma ação coletiva acionada no espaço de mediação de uma organização não governamental própria - a ONG CRILIBER - constituída décadas antes (MARCON, 2008). Cremos que tal protagonismo, bem como sua posição geográfica privilegiada - na capital do estado, próxima a órgãos públicos e entidades importantes - contribuirá com certa centralidade nas ações dos quilombolas no que tange a uma representação a nível estadual.

A CRILIBER, entidade representativa do quilombo urbano da Maloca, constituída já na década de 1980 , era ativa em ações voltadas para o combate ao racismo com ênfase nas crianças, "atuando na promoção dos direitos das populações afro-descendentes e realizando atividades culturais e eventos locais de debate contra a discriminação" (MARCON, 2008, p. 100). Uma destas ações

3o Secretaria de Políticas de Promoção da Igualdade Racial. Possui status de ministério e coordena o Programa Brasil Quilombola.

${ }^{31}$ Matéria sobre a assinatura do Decreto: http://infonet.com.br/politica/ler.asp?id=76745\&titulo=noticias. Em 23/05/2015 às 21:35.

${ }^{32} \mathrm{Os}$ arquivos foram verificados no site do governo do estado de Sergipe/Acervo legislativo.

33 Antônio Bonfim. CQ certificada pela FCP em 2006.

34 Xifroneze. CQ certificada pela FCP em 2005.

35 Luiz Bonfim. CQ Certificada pela FCP em 2007. 
ocorre desde a década de 90 e até hoje realiza-se um concurso da "Beleza Negra”, que ocorre todos os anos, conforme descrito por Menezes (2011):

\begin{abstract}
No caso da Beleza Negra CRILIBER as meninas da Maloca, tanto quanto as outras participantes, aprendem sobre a cultura africana, costumes e tradições relembrados no quilombo que serve de cenário para o concurso, assim como, das demais localidades do estado. Participam de oficinas de dança e música afro-brasileira, onde aprendem uma coreografia que irão encenar durante o concurso (MENEZES, 2011, p. 9, grifo nosso).
\end{abstract}

O trabalho empreendido contra a discriminação racial, feito por membros da CRILIBER -, agora também associado ao espaço do Comitê Gestor relacionado à valorização de uma identidade enfatizada em um (novo) entendimento sobre "a beleza de ser negro" -, tendo na culminância da realização do concurso da "Beleza Negra" seu ápice - ultrapassa o espaço restrito da capital do Estado, palco principal das ações do Movimento Negro, de modo geral. Abaixo, a visão do presidente da CRILIBER -representante quilombola no Comitê Gestor Quilombola - sobre a CEMQS:

\begin{abstract}
Eu discuto política de combate ao racismo, eu discuto uma política de pensar África, uma África sergipana. Se você for conversar, a turma lá [CEMQS], eles não têm a essência de África. Eles estão fazendo um movimento como se fosse MST (...). Falo pra você: se o movimento quilombola não entender o histórico do país como é que vai fazer enfrentamento com o Estado brasileiro? Se não conhece a colaboração da casa de cultura africana, da casa religiosa que é as filhas de Obá, lá em Laranjeiras, e outros mais, se não conhece a história dos nossos heróis africanos, como vai trazer melhoria para o povo? Como é que vai fazer enfrentamento com o governo? Ôh meu Deus! É fundamental você ter conhecimento da estória africana (...)36.
\end{abstract}

Com efeito, o distanciamento empreendido por lideranças quilombolas em relação ao "Comitê Gestor", configura-se em grande medida em estratégia a fim de realocar duas centralidades do/no movimento quilombola de até então: a do "Estado" - que embora não tivesse no Comitê Gestor um espaço normatizado, adquiria esta imagem de "governo"- e, a de um "pensar África", mais precisamente de um discurso que nem todos possuíam até então. A nomeação de uma nova entidade e modo de organização provocou um deslocamento que posicionava outros atores no protagonismo do diálogo com os atores quilombolas e, sobretudo, não-quilombolas, da rede quilombola no Estado, ao passo que também impunha separação - relativa - entre os "dois lados" que emergiram como opostos: o da CEMQS e o do "Comitê Gestor" (ou Maloca).

\title{
O MST ou MSK: lembranças de um movimento forjado.
}

É preciso situar, também, dentre as falas - recorrentes - que compunham a história de um movimento quilombola no Estado, aquelas capazes de impulsionar as lideranças a se "diferenciarem" dos agentes não-quilombolas da rede. Havia outra que "assombrava" algumas lideranças quilombolas, e que era sistematicamente relembrada em eventos - públicos ou restritos - enquanto um "alerta" contra uma possível "contaminação" dos quilombolas, que poderia se dar através de um relacionamento destes com o MST. Tratava-se de referência a um caso onde um ex-integrante do Movimento dos Trabalhadores Sem Terra tentou "forjar" um movimento quilombola - o MSK: Movimento Sergipano Kilombola -, bem como uma Comunidade Quilombola. Esta 
Comunidade "de fachada", embora certificada pela Fundação Cultural Palmares, atualmente encontra-se com o seu processo de RTID37 arquivado por intervenção do $\mathrm{MPF}_{3} 8$ e da própria $\mathrm{FCP}$. Estes órgãos, após receberem denúncias de quilombolas e setores do INCRA, procederam com ações administrativas e de perícia, e, a partir daí, pôde se constatar que se tratava de um acampamento39.

Embora o episódio fosse recorrentemente citado, o MST continuava sendo referência para algumas lideranças quilombolas. Algumas possuíam, inclusive, vínculos muito fortes com a entidade, além de relações de apoio de parlamentares que representavam os assentados da reforma agrária no Estado:

\begin{abstract}
Eu estou entrando assim [na CEMQS] porque minha comunidade foi certificada dia 25, mas já venho numa luta de muito tempo. Já tenho um conhecimento. Aí o pessoal "fala" do MST... Não, gente! A gente tem os mesmos ideais, os mesmos problemas, é a perseguição, é o político que entra ali e quer levar você "debaixo da chinela”. Eu estou militando porque minha mãe é assentada do MST e eu desde pequenininha que me entendo por gente que eu gostei de tá no meio, ali participando4o.
\end{abstract}

Ultimamente, inclusive, o principal parlamentar representante dos assentados da reforma agrária - "genérica" -, no Estado de Sergipe41, tem cruzado o "território" com outra parlamentar - do "movimento do Padre" uma das mais destacadas representantes da reforma agrária "étnica" em Sergipe42. A alteração do mandato do deputado, agora como "federal", parece torná-los, de algum modo, aliados, na medida em que não "concorrem" e isto também contribui, cada vez mais, com uma (re) aproximação de algumas lideranças no contexto da CEMQS. Com efeito, um "alerta" contra um relacionamento com o MST poderia ser relacionado, também, a um "alerta" contra um relacionamento com um dado parlamentar - ou "patrono" comprometido em defender certo movimento ou comunidade quilombola.

Sendo assim, é diante de um cenário de relacionamento diverso entre lideranças quilombolas e não-quilombolas, atuantes da rede quilombola, que a CEMQS se constitui e se reconstitui diariamente enquanto entidade que reivindica para si a primazia no direito de representar quilombos em Sergipe. Dito isto, críticas ao relacionamento dos atores quilombolas com o INCRA, com a Cáritas Diocesana de Propriá e com o MST são recorrentes, sobretudo por tratarem-se de agentes privilegiados na rede. O problema da desunião das lideranças, sempre citado pelas mesmas, todavia, pareceu encontrar na rede tanto a sua causa, quanto a chave para resolvê-lo.

37Relatório Técnico de Identificação e Delimitação do território de uma Comunidade Quilombola. É documento produzido pelo INCRA e compõe-se de diagnósticos feitos por antropólogo, engenheiro agrônomo, topógrafo, etc. As informações do documento circulam por diversos órgãos que validam, atestam, acrescentam, até a publicação de portaria feita pelo (a) presidente (a) do INCRA Nacional.

${ }_{38}^{8}$ O MPF, por meio de "Recomendação" n 01/2012, encaminhada ao INCRA em fevereiro de 2012, sugere que o mesmo não proceda com a elaboração do Relatório Antropológico, uma das principais peças que compõem o RTID. Recomenda que o órgão aguarde a manifestação da FCP e de peritos da "6 6 a Câmara de Coordenação e Revisão". Em uma de suas "considerações" consta "(...) eis que [a Comunidade Santo Antônio Canafístula] está sendo vista pelo movimento quilombola como um movimento de famílias que não obtiveram êxito com a Reforma Agrária e que estão "migrando" para o movimento quilombola".

39 A "comunidade" - ou o "acampamento" - está (ou estava) localizada no município de Propriá/SE e foi certificada pela

FCP em 10 de fevereiro de 2011

${ }^{40} \mathrm{Gressi}$. Evento III.

${ }^{41}$ João Daniel, Deputado federal do PT.

${ }^{42}$ Ana Lúcia Deputada estadual do PT. 


\section{Formatação da CEMQS}

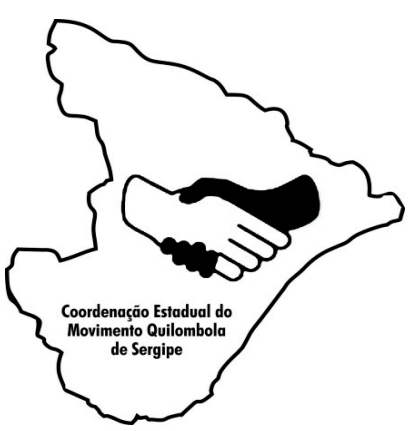

Figura $2^{43}$

A organização da CEMQS, enquanto entidade legítima de representação dos quilombolas a nível estadual, perpassa uma série de dilemas e ajustes. $\mathrm{O}$ primeiro deles, envolvia uma percepção sobre os "agentes externos". No entanto, para que a CEMQS pudesse ser criada foi preciso empreender uma ação ambígua: ao mesmo tempo romper com uma imagem e discurso negativo sobre os agentes e agências não-quilombolas, e, por outro lado, proceder com o estabelecimento de limites que impusessem certo distanciamento.

\section{O INCRA como principal "parceiro"?}

Esta primeira dicotomia, que está na gênese da CEMQS, foi aquela que estabelecia limites entre "movimento" e "governo" (INCRA e Comitê Gestor). Sobretudo pela excessiva proximidade entre lideranças e INCRA. Isto compunha, também, uma de suas justificativas a fim de legitimar a necessidade de uma entidade "a mais" - além do Comitê Gestor - ou uma entidade que fosse feita e constituída "só por quilombolas". O esforço por parte das lideranças em perceber e tornar evidente a diferenciação entre os dois lados, parece situar-se, essencialmente, na condição de "beneficiário" na qual estes atores ou qualquer quilombola estavam sujeitos.

Ao passo que o distanciamento do INCRA ou do "governo" se fazem necessários para uma "privacidade" da organização da "luta", a aproximação que se faz representada no símbolo do "aperto da mão amiga"-, diz respeito, em muito, às relações de dependência - ou de "parceria" - que extrapolam as atribuições meramente técnicas do órgão de seus agentes. As justificativas em torno da diferenciação entre "movimento" e "governo" oscilavam, assim, em torno da "cidade por projeto", inspiradas em princípios de justiça e mobilidade e, por outro, na "cidade doméstica", aquela em que a base da justiça ancora-se nas relações de amizade (BOLTANSKI; CHIAPELLO, 2009).

Desde o uso do espaço do auditório do INCRA para reunirem-se "entre eles”, até a participação de técnicos e/ou gestores em reuniões do próprio movimento, as conversas "privadas" da CEMQS, que extrapolam as paredes de um espaço físico e chegavam a pessoas ligadas à instituição, tudo isto, aos

43 Aperto da "mão amiga" sobre o mapa de Sergipe. Símbolo representativo da CEMQS: "O símbolo que eu estou propondo para a Coordenação Estadual do Movimento Quilombola de Sergipe é esta mão amiga sendo abraçada pelo Estado de Sergipe”. Wellington, coordenador-geral da CEMQS. Evento VI. 
poucos, irá trazer certo desconforto ou incômodo, fazendo com que os coordenadores cheguem a censurar, também, certo relacionamento pessoal das lideranças com alguns técnicos do INCRA, relacionamento este que pudesse pôr em risco encaminhamentos "coletivos" decididos pela "coordenação" em RMs.

Com efeito, a fim de elucidar tipos de atuação na rede quilombola, podemos separar, também, dois modos de atuação política presentes nas ações que "extrapolavam" a atuação técnica (não só) dos gestores do órgão para com estas populações de beneficiários da reforma agrária, aquelas as quais podem compor uma das lógicas de aproximação e afastamento dos quilombolas em relação ao INCRA. Ações próprias do redeiro - ou oportunista - e aquela realizada pelo "integrador de redes" - aquele que visa o bem comum - ambos conceitos descritos por Boltanski e Chiapello (2009). Cremos que seja o perfil do redeiro, o de alguns gestores do INCRA - aquele que investe sempre em uma centralização de sua posição na rede e pode ser descrito abaixo:

(...) mantendo separados os diferentes fragmentos de redes entre os quais conseguiu estabelecer uma ponte, o redeiro pode tornar-se passagem obrigatória. Sua atividade, assim, concorre para a formação de máfias, redes de corrupção, privilégios, apadrinhamentos, etc. (BOLTANSKI; CHIAPELLO, 2009, p. 367).

O redeiro do INCRA pode aproveitar sua posição de mediador central no aparato do Estado e na rede quilombola, a fim de manter, sobretudo, seu "cargo de confiança" seguro. Para isto, geralmente, precisa manter, também, o "rebanho" - os quilombolas - sob controle e, de preferência, também, disperso e/ou assumindo "inimigos" que aquele também tem. Em inúmeras falas das lideranças em seus momentos de reuniões mensais pudemos notar queixas ou censuras referentes à atuação de gestores do órgão, os quais visavam uma desarticulação - ou como eles diziam: a "desunião" do movimento quilombola no Estado. As ações de "desarticulação", em paradoxo, podiam ser dadas, geralmente, através de uma relação de amizade com algum coordenador quilombola ou com outras lideranças.

\section{Política Pública versus "Política de favorecimento pessoal”}

Outra dicotomia significativa que emerge após a constituição da CEMQS é aquela que estabelece uma distinção entre "política pública" e "política de favorecimento pessoal". Tal distinção denota uma preocupação, sobretudo, no que se refere ao uso específico do poder de "brokers" 44: "O broker age como intermediário da transação, prometendo obter, para o respondente, favores de terceiros" (MAYER, 2010, p.162), dados, neste caso, às lideranças quilombolas. Mais especificamente, certo controle sobre negociações do tipo "patronocliente" (WOLF, 2003, p. 109) com partidários e/ou com outros atores da rede.

As lideranças quilombolas são potenciais mediadoras das relações entre candidatos e comunitários, sobretudo em "tempo de política45", quando "ambos podem fazer promessas de campanha em época de eleição. O uso desta relação parecia muito comum, mas na CEMQS era preciso cumprir, cada vez mais, com algumas "obrigações: a primeira era a de selar, preferencialmente, relações partidárias com "quem historicamente tinha se posicionado do lado do povo

44"Os brokers são, assim, intermediários dos favores de oficiais do governo, ou detêm influência junto a poderosos concidadãos, e apresentam-se como capazes de acelerar os negócios do respondente" (MAYER, 2010, p. 162).

45De acordo com Moacir Palmeira (2014, p. 398): "Há um tempo da política que corresponde ao período eleitoral. É o período em que os políticos aparecem, em que se faz política, em que as facções políticas ganham contornos nítidos”. 
negro"46. A segunda era que tal aliança deveria ser convertida em beneficiamento "coletivo". Abaixo, a fala de uma das lideranças sobre como deveria ser o trabalho em tempo de eleição:

\begin{abstract}
O meu "trabalho de campo" na minha comunidade eu estou fazendo (...). Agora, essa questão de ter comunidades apoiando o outro partido [de direita]... Lá, a nossa campanha está em cima de dois deputados, com abertura pra quem quiser votar em outros, tem deputado estadual, tem deputado federal, (...) cada um tem seu gosto. Mas não vote em deputado lá do lado de lá [oposição ao PT], é isso que estou fazendo 47 .
\end{abstract}

Usaremos aqui, ligeiramente, este termo nativo (trabalho de campo) para designar as ações de brokerage (MAYER, 2010) realizadas pelas próprias lideranças quilombolas na Comunidade Quilombola a que pertencem a fim de atrair votos para os candidatos para quem "trabalham" ou simplesmente apoiam. Acima, podemos dizer que a liderança expressa qual deve ser o modo correto de exercer o trabalho de campo ou brokerage. Todavia, tais cobranças eram, também, requeridas indiretamente - através das conversas mais informas ou após as RMs - não somente pelos próprios coordenadores, mas, sobretudo, por aqueles "parceiros" não-quilombolas vinculados direta ou indiretamente ao PT que eram pertencentes à rede.

\begin{abstract}
Patrocinar candidaturas de pessoas que tradicionalmente perseguiram é negar nossa própria história. Quem historicamente nos defende está aqui [apontando para um panfleto com as propostas de Dilma e do PT]. A proposta é essa aqui. Aqui! Quem é que historicamente está do nosso lado, na história do Brasil?48.
\end{abstract}

\title{
Considerações Finais
}

Não somente o anseio pelo acesso aos direitos sociais e às políticas públicas impulsionaram as lideranças quilombolas a organizarem um movimento "só de quilombolas". Mas, sobretudo, pelo direito à voz ou autorepresentação pública. Ademais, ao acompanhar o processo de organização da CEMQS, foi possível notar que além da permeabilidade entre a CEMQS e a rede quilombola, a existência de "uma fala só" - se entendida como metáfora, a fim de impor distanciamento dos quilombolas dos principais mediadores nãoquilombolas da rede - enquanto antídoto para a resolução do problema de representação da causa quilombola "pelos próprios quilombolas" não garantiu o direito à voz própria em cenários e arenas políticas de Sergipe.

Ao contrário, em paradoxo, o contato e interação com uma rede diversa, outrora - e, ainda - tida como concorrente, e de atores com interesses variados foi o único modo de lhes garantir uma fala mínima. Desde que as relações com esta rede fossem, também, mediadas por uma organização capaz de agregar dentro dela as várias outras vozes que não pareciam ouvidas anteriormente “(...) e quando fundou esse movimento aqui a gente teve esse poder de falar (...) [antes] era um movimento que eu não gostei. Aqui a gente senta, aqui a gente conversa, aqui a gente discute, a gente tem fala e tem opinião" 49 - esta era permitida.

${ }^{46}$ Fala do representante do MNU - um dos “convidados" em RM da CEMQS. Evento XIII.

47 Liderança quilombola de Pontal da Barra. Evento XIII.

${ }^{48}$ Carlos, representante nacional do MNU em Sergipe. Sala de reuniões do CONSEAN. Evento XIII.

49 Zé Raimundo. Evento XV. 
Por um lado, na medida em que cada comunidade quilombola poderia funcionar como um movimento à parte, já que a "estrutura" para que se mantivessem em movimento poderia ser dada, também, por um "patrono" ou conjunto de "apoiadores", o desafio de criar um movimento de "uma fala só", era, em grande medida, o desafio de aglutinar em um mesmo espaço os diferentes "patronos" - no qual o símbolo do aperto da mão amiga pode servir de metáfora - que reivindicam um eleitorado em espaços locais, precisando do "trabalho de campo" de algumas lideranças quilombolas. Neste ponto, uma das saídas encontradas pela CEMQS para o estabelecimento de um movimento de "uma fala só", parece-nos que pôde ser ilustrado através do dilema estabelecido entre "política pública" e "política de beneficiamento pessoal" - evento XIII que cede direito automático a todas as lideranças quilombolas que pretendam estabelecer relações com partidários do PT - "aqueles que historicamente defenderam a luta do povo negro desse país" 50 .

É preciso enfatizar que, a fim de obterem voz pública, foi preciso, primeiro, a organização de um falar "interno" que os levou a empreender - junto a uma série de diferenciações - uma ação inicial de "separação" do Comitê Gestor e do INCRA. Do primeiro, realocando a centralidade do urbano em detrimento do rural e de um "pensar África" - ou discurso restrito a poucos. O distanciamento - relativo - do INCRA, por outro lado, pôde ser caracterizado, sobretudo, através do esforço em usar um novo espaço - relativamente privado - para reunirem-se. A posição central dada ao INCRA, tendo em vista o seu lugar de destaque na rede quilombola, tributária do "lugar legítimo", daquele que detinha, sobretudo, o saber técnico - que era o mesmo que ter poder na "arena pública” (CEFAI, MELLO, MOTA e VEIGA, 2011) em torno da causa quilombola no Estado - parecia amortecer a necessidade de organização política das lideranças quilombolas, quando estas requeriam seus direitos sociais.

\section{Bibliografia}

ANJOS, José Carlos dos; SILVA, Paulo Sérgio da. A rede quilombola como espaço de ação política. In: NEVES, D. P. (org.). Desenvolvimento social $e$ mediadores políticos. Porto Alegre: UFRGS, pp. 155-172., 2008.

BARNES; J. A. Redes sociais e processo político. In: FELDMAN-BIANCO, Bela (org.). Antropologia das sociedades contemporâneas: métodos. São Paulo: UNESP, pp.171-204, 2010.

BOLTANSKI, Luc; CHIAPELLO, Évil. O novo espírito do capitalismo. Tradução Ivone C. Benedetti. São Paulo: Martins Fontes. 2009.

BRASIL. Casa Civil. Decreto n. 4.887, de 20 de novembro de 2003. Regulamenta o procedimento para identificação, reconhecimento, delimitação, demarcação e titulação das terras ocupadas por remanescentes das comunidades dos quilombos de que trata o art. 68 do Ato das Disposições Constitucionais Transitórias. Diário Oficial da União, Brasília, DF, 21 nov, 2003a. 
Decreto n. 5.051, de 19 de abril de 2004. Promulga a Convenção ${ }^{\circ}$ 169, da Organização Internacional do trabalho- OIT sobre povos Indígenas e Tribais, $2004^{\mathrm{a}}$.

Decreto n. 6.261, de 20 de novembro de 2007. Dispõe sobre a gestão integrada para o desenvolvimento da Agenda Social Quilombola no âmbito do Programa Brasil Quilombola, e dá outras providências, 2007.

Lei 12.288 de 20 de Julho de 201O. Institui o Estatuto da Igualdade Racial; altera as leis nos 7716 de 5 de janeiro de 1989, 9.029 de 13 de abril de 1995, 7.347, de 24 de julho de 1985, e 10778, de 24 de novembro. 2010.

Ministério Público Federal. Procuradoria da República no Estado de Sergipe. Recomendação ao INCRA, $N^{o}$ O1/2O12, fevereiro., $2012 \mathrm{a}$.

Secretaria de Políticas Especiais de Promoção à Igualdade Racial. Programa Brasil Quilombola, 2004b.

Programa Brasil Quilombola. Diagnóstico de Ações Realizadas, Julho, 2012b.

CASTRO, Camila Penna de. (2013), Movimentos sociais e mudanças institucionais: o impacto dos movimentos de luta pela reforma agrária nas práticas do Instituto Nacional de Colonização e Reforma Agrária. Anais do $37^{\circ}$ Encontro Anual da ANPOCS. Águas de Lindóia.

O Estado como um ator heterogêneo: implementação de políticas públicas no INCRA de Marabá. IX Encontro da ABCP, 04-07, Brasília, agosto, 2014.

CEFAÏ, Daniel; MELLO, Marco Antônio da Silva; MOTA, Fábio Reis; VEIGA, Felipe Verocan.. Introdução: Arenas Públicas: Por uma etnografia da vida associativa. In: CEFAÏ, Daniel; MELLO, Marco Antônio da Silva; MOTA, Fábio Reis; VEIGA, Felipe Verocan (org.). Arenas Públicas: Por uma etnografia da vida associativa. Niterói: Universidade Federal Fluminense, 2011.

DODIER, Nicolas. Agir em diversos mundos. In: de CARVALHO, Maria do Carmo Brant (org.) Teorias da ação em debate. São Paulo: Cortez; FAPESP: Instituto de Estudos Especiais, PUC, 1993.

FERREIRA, Andrey F. Diversidade e desigualdade no Brasil dos 500 anos: etnografia da Conferência e Marcha Indígena. In: LIMA, Roberto Kant de (org.). Antropologia e Direitos Humanos 5. Brasília; Rio de Janeiro: ABA; Booklink. 2008.

GOHN, Maria Glória. “Movimentos sociais na contemporaneidade”. In: Revista Brasileira de Educação; v. 16 n. 47 maio-ago, 2011.

LATOUR, Bruno. Crise. In: LATOUR, Bruno. Jamais fomos modernos: ensaio de antropologia simétrica. Rio de Janeiro: Editora 34, pp. 7-17, 1994.

. Reagregando o social. Uma introdução à teoria ator-rede. Salvador: Edufba, 2012; Bauru/SP: Edusc. 
MARCON, Frank N. Quilombo urbano da Maloca. In: LEITE, Rogério P. (org.). Cultura e vida urbana: ensaios sobre a cidade. São Cristóvão/SE: EdUFS, 2008.

MAYER, Adrian C. A importância dos quase grupos no estudo das sociedades complexas. In: FELDMAN-BIANCO, Bela (org.). Antropologia das Sociedades Contemporâneas: Métodos. São Paulo: UNESP, pp. 139-170, 2010.

MENEZES, Tacyane Lima de. A invenção de uma África e de um jeito de ser belo. V Fórum Identidades e Alteridades: I Congresso Nacional de educação $e$ diversidade. UFS/Itabaiana . De o8 a 10 de setembro de 2011.

NEVES, Delma P. (org.). Desenvolvimento social e mediadores políticos. Porto Alegre: UFRGS, 2008. pp. 155-172.

PALMEIRA, Moacir. Memorial do Candidato. Revista Mana, Rio de Janeiro, v. 20, n. 2, p. 371-409, agosto, 2014. Disponível em <http://www.scielo.br/scielo.php?script=sci_arttext\&pid=So10493132014000200371\&lng=en\&nrm=iso $>$.

SANTOS, Carlos Alexandre B. Plínio dos. (2014), Os estudos sobre comunidades negras rurais (Quilombolas) no Brasil. In: CAVIGNAC, Julie; MACÊDO, Muirakytan K. (Organizadores). Tronco, ramos e raízes! História e patrimônio cultural no Seridó negro. Brasília: ABA; Natal: Flor do Sal; EDUFRN; 2014.

SERGIPE. Governo de Sergipe. Programa de Desenvolvimento das Comunidades Quilombolas do Estado de Sergipe. $1^{o}$ Relatório do Programa, novembro, 2012.

WAGNER, Roy. Existem grupos sociais nas terras altas da Nova Guiné? Revista Cadernos de Campo, São Paulo, n.19, p. 1-384, 2010 .

. A invenção da cultura. Trad. Marcela Coelho de Souza e Alexandre Morales. São Paulo: Cosac Naify, 2010. 253pp, 2010b.

WOLF, Eric. Aspectos das relações de grupos em uma sociedade complexa: México, parentesco, amizade e relações patrono-cliente em sociedades complexas. In: FELDMAN-BIANCO, Bela; RIBEIRO, Gustavo Lins (orgs.). Antropologia e poder. Tradução Pedro Maia Soares. Brasília: UnB; São Paulo: Imprensa Oficial do Estado de São Paulo; Campinas/SP: Unicamp, 2003.

\section{Recebido em 16/o8/2016.} Aprovado em 13/12/2016. 